\title{
PENGARUH PEMBERIAN EKSTRAK BAWANG MERAH DAN KECAMBAH DENGAN PEMBERIAN PUPUK CAIR HAYATI TERHADAP PERTUMBUHAN SEEDLING MANGGIS (Garcinia mangostana L.)
}

\author{
Effect of Shallot and Sprout Extracts Combined with Bio-Liquid Fertilizer on \\ the Growth of Mangosteen Seedlings (Garcinia mangostana L.) \\ Rugayah $^{1 *}$, Agus Karyanto ${ }^{2}$, Ermawati ${ }^{1}$, Dewi Suselawati ${ }^{2}$ \\ ${ }^{1}$ Jurusan Agroteknologi, Fakultas Pertanian, Universitas Lampung \\ ${ }^{2}$ Jurusan Agronomi dan Hortikultura, Fakultas Pertanian, Universitas Lampung \\ Jl. Sumantri Brojonegoro No 1 Gedung Meneng, Bandar Lampung 35145 \\ *E-mail korespondensi: rugayah.1961@fp.unila.ac.id
}

\begin{abstract}
ABSTRAK
Bibit manggis (Garcinia mangostana $\mathrm{L}$ ) asal biji, atau biasa disebut seedling, memiliki akar lateral yang relatif minim dan sedikit bulu akar sehingga pertumbuhannya lambat. Untuk itu perlu dilakukan upaya agar bibit manggis dapat memiliki sistem perakaran yang baik melalui penambahan zat pengatur tumbuh alami. Tujuan penelitian ini adalah untuk mengetahui pengaruh pemberian ekstrak bawang merah, campuran ekstrak bawang merah dan kecambah kacang hijau yang dikombinasikan dengan pupuk cair hayati terhadap pertumbuhan seedling manggis. Penelitian ini dilaksanakan di rumah kaca Hortikultura Fakultas Pertanian Universitas Lampung pada bulan Maret 2020-Juli 2020, disusun secara faktorial ( 3 x 2) dalam Rancangan Acak Kelompok (RAK) dengan tiga ulangan. Faktor pertama adalah perlakuan zpt alami: tanpa ekstrak, ekstrak bawang merah $400 \mathrm{~g} / \mathrm{L}$, dan ekstrak campuran bawang merah $200 \mathrm{~g} / \mathrm{L}$ dan kecambah kacang hijau $200 \mathrm{~g} / \mathrm{L}$. Faktor kedua adalah pemberian pupuk hayati yaitu tanpa pupuk hayati dan $15 \mathrm{ml} / \mathrm{L}$ ). Hasil uji BNT menunjukkan bahwa pemberian ekstrak campuran bawang merah dan kecambah kacang hijau cenderung menghasilkan pertumbuhan lebih baik yang dapat dilihat dari nilai rata-rata tertinggi pada variabel tinggi tanaman $6,04 \mathrm{~cm}$, diameterbatang 2,93 mm, dan jumlah akar sekunder. Perlakuan ekstrak campuran bawang merah dan kecambahkacang hijau juga meningkatkan luas daun terlebar dengan selisih $3,5 \mathrm{~cm}^{2}$ dibandingkan dengan kontrol.
\end{abstract}

Kata kunci: Ekstrak, bawang merah, kecambah kacang hijau, manggis, ZPT alami

\section{ABSTRACT}

Mangosteen (Garcinia mangostana L) seeds from seed, or commonly called seedling, have relatively few lateral roots and are poor in root hairs so that their growth is slow (having a long juvenile period of up to 10-15 years). For this reason, it is necessary to make efforts so that mangosteen seedlings can have a good root system through the addition of natural growth regulators. The purpose of this study was to determine the effect of red onion extract, a mixture of onion extract and mung bean sprouts combined with biological liquid fertilizer on the growth of mangosteen seedling. This research was carried out in the Horticulture FP greenhouse in March 2020-July 2020. This study was arranged in a factorial $\left(\begin{array}{l}3 \\ x\end{array} 2\right)$ in a Randomized Block Design (RAK) with three replications. The first factor was natural ZPT treatment: without extract, red onion extract $400 \mathrm{~g} / \mathrm{L}$, and mixed extract of onion $200 \mathrm{~g} / \mathrm{L}$ and green bean sprouts $200 \mathrm{~g} / \mathrm{L}$. The second factor is the provision of biological fertilizers, namely without biological fertilizers and $15 \mathrm{ml} / \mathrm{L}$ ). The results showed that the administration of mixed extracts of shallots and mung bean sprouts tended to have better growth which could be seen from the highest average value for the variable plant height $6.04 \mathrm{~cm}$, stem diameter $2.93 \mathrm{~mm}$, and the number of secondary roots. The mixed extract treatment of shallots and mung bean sprouts also increased the widest leaf area by a difference of $3.5 \mathrm{~cm}^{2}$ compared to the control.

Key words: extract of shallot, green bean sprout, growth regulator, mangosteen 


\section{PENDAHULUAN}

Garcinia merupakan salah satu genus dari famili Gutiferae/Clussiaceae dan anggotanya tersebar luas di wilayah tropik dunia. Manfaat dari spesies-spesies dalam genus Garcinia yaitu sebagai penghasil buah yang dapat di konsumsi, minyak, dan obat. Manggis (Garcinia mangostana L.) merupakan salah satu spesies dari genus ini, buahnya dikenal dengan sebutan queen of fruits (Aizat et al., 2019).

Berdasarkan data Direktorat Jenderal Hortikultura volume ekspor buah manggis di Indonesia pada tahun 2018 mencapai 38.841,37 ton dan pada tahun 2019 mencapai 27.797,08 ton. Produksi manggis dalam negeri pada tahun 2018 mencapai angka 228,148 ton dan pada tahun 2019 mencapai 246,476 ton dengan pertumbuhan selama tahun 2018-2019 sebesar 8.03\%. Produksi manggis di Provinsi Lampung sendiri pada tahun 2018 mencapai angka 2,932 ton dan pada tahun 2019 sebesar 15,249 ton. Manggis tergolong buah eksotik Asia, sehingga harganya di pasar internasional cukup menarik. Pangsa ekspor manggis Indonesia adalah Taiwan, Singapura, Malaysia, Hongkong, dan Timur Tengah (Arab Saudi dan Uni Emirat Arab).

Permasalahan dalam budidaya tanaman manggis yaitu sangat lambatnya laju tumbuh baik pada fase bibit maupun setelah ditanam di lapang. Lambatnya laju pertumbuhan tanaman manggis diakibatkan kurang baiknya sistem perakaran. Tanaman manggis mempunyai akar tunggang yang panjang dan kuat, tetapi memiliki akar-akar lateral yang relatif minim dan sedikit bulubulu akar. Hal ini menyebabkan terbatasnya kemampuan tanaman manggis dalam menyerap air dan hara dari dalam tanah, sehingga pertumbuhan manggis sangat lambat, laju fotosintesis rendah, dan rendahnya laju pembelahan sel pada meristem pucuk (Syah et al., 2007).

Upaya yang dapat dilakukan untuk mempercepat pertumbuhan bibit manggis, terutama sistem perakarannya yaitu dengan penambahan ZPT alami berupa ekstrak kecambah kacang hijau dan ekstrak bawang merah. Bahan alami ini diduga dapat membantu dalam pertumbuhan akar sehingga tanaman dapat tumbuh dengan baik. Penggunaan ZPT alami ini diharapkan dapat dicari formulasinya dan dapat memacu dalam memperbaiki sistem perakaran pada bibit tanaman manggis. Penelitian ini akan berguna bagi petani dalam mendapatkan bibit manggis yang berkualitas dan cepat siap tanam.

Zat pengatur tumbuh alami yang dapat digunakan yaitu ekstrak bawang merah dan kecambah kacang hijau sebagai sumber auksin yang diperlukan untuk memacu tumbuhnya akar. Beberapa penelitian menunjukkan bahwa penambahan auksin eksogen akan meningkatkan kandungan auksin endogen dalam jaringan setek sehingga mampu menginisiasi sel untuk tumbuh dan berkembang yang selanjutnya akan berdiferensiasi membentuk organ seperti akar (Yanengga dan Tuhuteru, 2020). Penggunaan ZPT alami seperti umbi bawang merah memiliki kandungan vitamin B1, thiamin, riboflavin, asam nikotinat, serta mengandung auksin rhizokalin. Ekstrak umbi bawang merah berfungsi memperlancar metabolisme pada jaringan tumbuhan dan juga dapat bersifat fungisida dan bakterisida (Sofwan et al., 2018).

Menurut penelitian Tarigan et al. (2017), konsentrasi ekstrak bawang merah $60 \%$ memberikan hasil yang lebih baik terhadap persentase stek hidup, munculnya tunas, panjang tunas, jumlah daun, jumlah akar, panjang akar, dan volume akar pada stek lada. Keefektifan zat pengatur tumbuh dari ekstrak umbi bawang merah dipengaruhi oleh jenis tanaman, bagian tanaman, dan stadia perkembangan tanaman. Ekstrak kecambah kacang hijau memiliki konsentrasi senyawa zat pengaturtumbuh auksin 1,68 mg/L, giberelin 39,94 mg/L, dan sitokinin 96,26 $\mathrm{mg} / \mathrm{L}$. Olehkarrena itu ekstrak kecambah kacang hijau banyak 
digunakan sebagai alternatif ZPT alami (Pamungkas dan Rudin, 2020).Berdasarkan penelitian Nabila et al. (2018) pemberian ekstrak kecambah dengan konsentrasi 100 $\mathrm{g} / \mathrm{L}$ menghasilkan jumlah akar sekunder lebih tinggi di bandingkan dengan pemberian ekstrak kecambah pada konsentrasi $200 \mathrm{~g} / \mathrm{L}$ dan konsentrasi $300 \mathrm{~g} / \mathrm{L}$.

\section{METODE PENELITIAN}

Penelitian ini dilaksanakan di rumah kaca Hortikultura Fakultas Pertanian Universitas Lampung, dimulai pada bulan Maret dan berakhir pada bulan Juli 2020.Bahan tanam yang digunakan pada penelitian ini berupa benih manggis yang berasal dari buah manggis asal Sukadanaham. Media tanam yang digunakan berupa tanah, sekam bakar, kompos, pupuk kandang, aquades, fungisida bahan aktif Mancozeb 80\%, pupuk hayati, ekstrak bawang merah, dan ekstrak kecambah (Gambar 1). Alat-alat yang digunakan pada penelitian ini adalah keranjang semai, polybag, cangkul, penggaris, gembor, kertas label, timbangan analitik, blender, jangka sorong, saringan, gelas ukur, kamera, alat tulis, ayakan, dan heater.

Penelitian ini disusun secara faktorial (3 x 2) dalam Rancangan Acak Kelompok (RAK), dengan tiga ulangan. Faktor pertama tanpa ekstrak (B0), ekstrak bawang merah $400 \mathrm{~g} / \mathrm{L}$ (B1), dan ekstrak campuran bawang merah $200 \mathrm{~g} / \mathrm{L}$ dan kecambah $200 \mathrm{~g} / \mathrm{L}$ (B2). Faktor kedua pemberian pupuk hayati yaitu tanpa pupuk hayati (P0) dan pemberian pupuk hayati dengan konsentrasi $15 \mathrm{ml} / \mathrm{L}$ (P1). Pengelompokan berdasarkan bobot benih yaitu 1-1,3 g, 1,4-1,9 g, dan $\geq 2 \mathrm{~g}$. Setiap kelompok terdiri dari 6 perlakuan, setiap perlakuan terdiri dari 4 tanaman manggis, sehingga didapat 72 satuan percobaan (Gambar 2). Homogenitas ragam antar perlakuan diuji dengan menggunakan uji Barlett dan aditivitas data diuji dengan menggunakan uji Tukey. Setelah kedua asumsi ini terpenuhi maka dilakukan analisis ragam dan dilanjutkan pemisahan nilai tengah dengan BNT (Beda Nyata Terkecil) yaitu untuk mengetahui pengaruh masingmasing perlakuan pada taraf nyata $5 \%$.

Penelitian ini dilaksanakan melalui beberapa tahapan, yaitu pembuatan media semai yang merupakan campuran kompos, tanah dan arang sekam dengan perbandingan $(1: 1: 1 \mathrm{v} / \mathrm{v})$. Penanaman benih manggis berasal dari buah yang telah masak pada stadium 4-5 untuk diambil bijinya.

Pembuatan media tanam yaitu campuran tanah, kompos, pupuk kandang, dan sekam dengan perbandingan $(2: 1: 1: 1$ v/v). Pindah tanam bibit manggis di lakukan pada umur 25 hari setelah semai, ke dalam polybag dengan ukuran $10 \mathrm{~cm}$ x $30 \mathrm{~cm}$, pemindahanbibit manggis dilakukan dengan mengelompokkan sesuai bobot awal benih (terkecil 1-1,3 g, sedang 1,4-1,9 g, dan besar $2 \mathrm{~g}$ ). Larutan ekstrak bawang merah dibuat dengan bahan dasar umbi bawang merah yang ditunaskan terlebih dahulu selama 4 minggu. Umbi bawang merah yang sudah disemai dan dibersihkan kemudian ditimbang $200 \mathrm{~g}$ untuk diblender dengan menambahkan 1 liter air dan disaring.

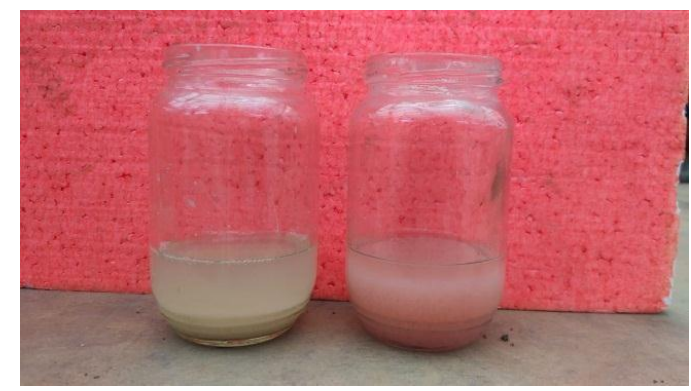

Gambar 1. Ekstrak bawang dan kecambah sebagai ZPT alami

Ekstrak kecambah kacang hijau yang digunakan yaitu dengan konsentrasi $200 \mathrm{~g} / \mathrm{L}$. Kecambah kacang hijau sebanyak 200 g dihaluskan dengan menggunakan blender, kemudian disaring untuk diambil ekstraknya. Setelah disaring kemudian ekstrak kecambah ditera ditambahkan air sehingga volumenya menjadi 1 liter. Ekstrak kecambah kacang hijau kemudian 
dipanaskan hingga mendidih, setelah suhunya normal kemudian dicampur dengan ekstrak bawang merah 200 g/L. Kedua ekstrak diaduk sehingga homogen, lalu diaplikasikan dengan cara disiramkan ke arah pangkal batang seedlings mangis sebanyak $15 \mathrm{ml} /$ tanaman. Aplikasi ZPT alami ini dilakukan sebanyak dua kali pemberian dengan interval 1 minggu, jadi total ZPT alami yang diterima sebanyak 30 $\mathrm{ml} /$ tanaman.

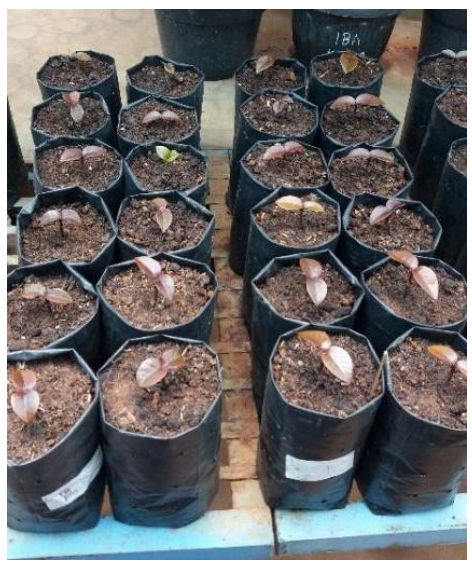

Gambar 2. Plot percobaan

Pupuk cair hayati yang digunakan yaitu merk dagang Grikulan Plus. Aplikasi pupuk cair hayati dilakukan sebanyak 3 kali dengan konsentrasi $15 \mathrm{ml} / \mathrm{L}$, dengan aplikasipertama pada media 3 hari sebelum pindah tanam seedling manggis sebanyak $30 \mathrm{ml} /$ tanaman, aplikasi kedua setelah 10 hari pindah tanam dengan dosis 40 $\mathrm{ml} /$ tanaman, dan aplikasi terakhir pada 6 minggu setelah tanam dengan dosis 50 $\mathrm{ml} /$ tanaman. Total keseluruhan pemberian pupuk cair hayati sebanyak 120 $\mathrm{ml} /$ tanaman.

Perawatan tanaman meliputi penyiraman, penyiangann gulma, dan pemberian insektisida serta fungisida. Penyiraman seedling manggis dilakukan dua hari sekali sampai media tanam menjadi lembab. Penyiangan dilakukan secara manual dengan mencabut gulma yang tumbuh di sekitar seedling manggis. Pemberian insektisida dengan bahan aktif Karbofuran 3\% untuk mengendalikan hama dengan cara ditabur ke media tanam dan fungisida dengan bahan aktif mancozeb $80 \%$ untuk pengendalian fungi dengan cara di semprot pada tanaman.

\section{HASIL DAN PEMBAHASAN}

Hasil penelitian menunjukkan bahwa pemberian zat pengatur tumbuh ekstrak bawang merah dan campuran bawang merah dengan kecambah pada seedling manggis hanya berpengaruh nyata pada luas daun, sedangkan perlakuan pemberian pupuk cair hayati berpengaruh nyata pada jumlah akar sekunder seedling manggis (Tabel 1). Interaksi antara zat pengatur tumbuh alami dengan pupuk cair hayati tidak menunjukkan adanya pengaruh yang nyata pada semua variabel pengamatan. Pengelompokan berdasarkan bobot biji berpengaruh nyata pada tinggi tanaman dan luas daun.

\section{Tinggi Tanaman}

Pemberian zat pengatur tumbuh alami dan pupuk cair hayati tidak berpengaruh nyata terhadap tinggi tanaman.Secara umum pertumbuhan seedlingsmanggis pada setiap perlakuan cenderung mengalami peningkatan. Penambahan tinggi seedling manggis terus mengalami peningkatan pada umur 2 MST - 10 MST, kemudian penambahan tinggi melambat pada umur 10 MST - 12 MST akibat serangan uret yang dapat dilihat pada gambar 3 (pembongkaran media padaminggu ke-10) dan pada umur 14 MST pertumbuhan tinggi seedling mengalami peningkatan kembali.

Berdasarkan hasil analisis ragam pemberian zat pengatur tumbuh alami ekstrak bawang merah dan kecambah kacang hijau dengan pemberian pupuk hayati tidak berpengaruh nyata terhadap variabel tinggi tanaman pada umur 14 MST. Hasil rata-rata tinggi tanaman pada 14 MST yaitu $5,77 \mathrm{~cm}$ dengan kisaran tertinggi pada perlakuan $\mathrm{B} 2 \mathrm{P} 0$ (ekstrak campuran bawang merah $200 \mathrm{~g} / \mathrm{l}$ dan kecambah $200 \mathrm{~g} / \mathrm{l}$ tanpa pemberian pupuk hayati $0 \mathrm{ml} / \mathrm{l}$ ) sebesar 6,04 $\mathrm{cm}$ dan terendah pada perlakuan $\mathrm{B} 0 \mathrm{P} 0$ (kontrol) sebesar 5,42cm (Tabel 3). 
Tabel 1. Rekapitulasi hasil analisis ragam pengaruh ekstrak bawang merah, campuran ekstrak bawangmerah dan kecambah, dengan pupuk hayati pada pertumbuhan seedling manggis.

\begin{tabular}{llllll}
\hline No & Variabel Pengamatan & Kelompok & $\begin{array}{l}\text { ZPT Alami } \\
(\mathrm{K})\end{array}$ & $\begin{array}{l}\text { Pupuk Hayati } \\
(\mathrm{P})\end{array}$ & $\begin{array}{l}\text { Interaksi } \\
(\mathrm{K} \mathrm{x} \mathrm{P})\end{array}$ \\
\hline 1. & Tinggi tanaman $(\mathrm{cm})$ & $*$ & tn & tn & tn \\
2. & Jumlah daun (helai) & tn & tn & tn & tn \\
3. & Luas daun $\left(\mathrm{cm}^{2}\right)$ & $*$ & $*$ & tn & tn \\
4. & Diameter batang $(\mathrm{mm})$ & tn & tn & tn & tn \\
5. & Panjang akar primer & tn & tn & tn & tn \\
& $(\mathrm{cm})$ & & & $*$ & tn \\
6. & Jumlah akar & tn & tn & tn & tn \\
7. & Bobot basah $(\mathrm{g})$ & tn & tn & tn & \\
\hline
\end{tabular}

Keterangan: tn $=$ tidak nyata, $*=$ berbeda pada $\alpha 5 \%$

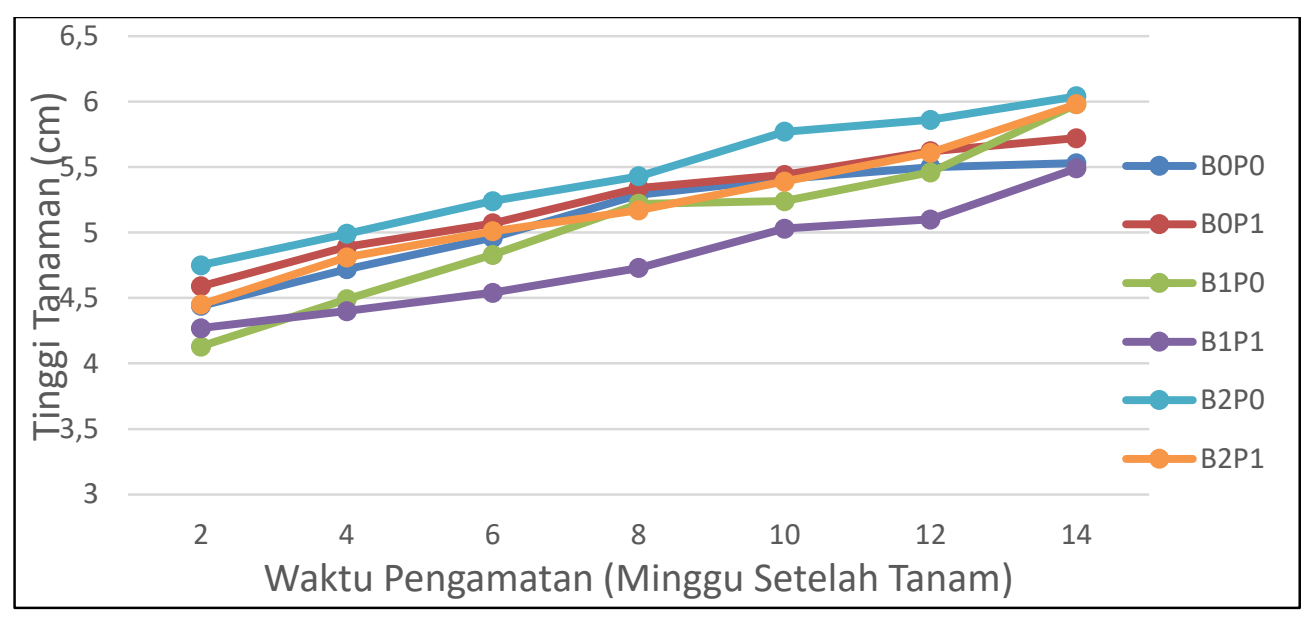

Keterangan:

B0P0 = Tanpa zpt alami dan tanpa pupuk hayati, B0P1 = Tanpa zpt alami dan pupuk cair hayati 120 $\mathrm{ml}, \mathrm{B} 1 \mathrm{P} 0=$ Ekstrak bawang merah $400 \mathrm{~g} / \mathrm{L}$ dan tanpa pupuk hayati, B1P1 = Ekstrak bawang merah $400 \mathrm{~g} / \mathrm{L}$ dan pupuk cair hayati $120 \mathrm{ml}, \mathrm{B} 2 \mathrm{P} 0=$ Ekstrak bawang merah $200 \mathrm{~g} / \mathrm{L}+$ kecambah $200 \mathrm{~g} / \mathrm{L}$ dan tanpa pupuk cair hayati, B2P1 = Ekstrak bawang merah $200 \mathrm{~g} / \mathrm{L}+$ kecambah $200 \mathrm{~g} / \mathrm{L}$ dan pupuk cair hayati $120 \mathrm{ml}$.

Gambar 3. Grafik tinggi tanaman seedling manggis

\section{Jumlah Daun}

Pemberian zat pengatur tumbuh alami ekstrak bawang merah dan campuran ekstrak bawang merah dengan kecambah pada seedling manggis tidak berpengaruh nyata terhadap jumlah daun. Peningkatan jumlah daun pada seedling manggis terjadi pada umur 2 MST hingga 10 MST, kemudian penambahan jumlah daun terhenti pada umur 12 MST dan kembali mengalami peningkatan pada umur 14 MST
Berdasarkan hasil analisis ragam zat pengatur tumbuh alami ekstrak bawang merah dan campuran ektrak bawang merah dengan kecambah kacang hijau tidak berpengaruh nyata terhadap jumlah daun, begitupula interaksi keduanya tidak menunjukkan adanya pengaruh yang nyata. Rata-rata jumlah daun pada akhir pengamatan sebesar 3,26 helai dengan kisaran jumlah daun tertinggi pada perlakuan B1P1 (ekstrak bawang merah 400 $\mathrm{g} / \mathrm{l}+$ dengan pupuk cair $15 \mathrm{ml} / \mathrm{l}$ ) sebesar 3,83 
helai dan terendah pada perlakuan B0P0 (kontrol) dan B1P0 (ekstrak bawang merah $400 \mathrm{~g} / \mathrm{l}+$ tanpa pemberian pupuk cair $0 \mathrm{ml} / \mathrm{l}$ ) sebesar 3,00 helai.

\section{Diameter Batang}

Hasil analisis ragam menunjukkan bahwa pemberian zat pengatur tumbuh alami dan pupuk cair hayati tidak berpengaruh nyata terhadap variabel pengamatan diameter batang seedling manggis. Rata-rata diameter batang pada 14 MST yaitu sebesar 2,47 mm. Kisaran tertinggi pada perlakuan B2P0 (Campuran ekstrak bawang merah dengan kecambah $200 \mathrm{~g} / \mathrm{l}+200 \mathrm{~g} / \mathrm{l}$ dan tanpa pemberian pupuk cair hayati) dengan nilai $2,93 \mathrm{~mm}$, sedangkan kisaran terendah pada perlakuan B0P1 (tanpa zat pengatur tumbuh alami $0 \mathrm{~g} / \mathrm{l}$ dengan pupuk cair $15 \mathrm{ml} / \mathrm{l}$ ) sebesar 2,13mm.

\section{Luas Daun}

Berdasarkan hasil analisis ragam menunjukkan bahwa pemberian zat pengatur tumbuh alami berpengaruh nyata terhadap luas daun, sedangkan pada perlakuan baik diberi pupuk cair hayati maupun tanpa pupuk cair hayati tidak memberikan pengaruh pada luas daun seedling manggis. Hasil uji BNT (Tabel 2) menunjukkan bahwa perlakuan campuran eksrak bawang merah dan kecambah menghasilkan luas daun yang terlebar dengan nilai $14,65 \mathrm{~cm}^{2}$.

\section{Jumlah Akar Sekunder}

Berdasarkan hasil uji BNT pada taraf $5 \%$ menunjukkan bahwa perlakuan pemberian pupuk cair hayati menunjukkan adanya perbedaan anatara yang diberi pupuk dengan tanpa pupuk. Perlakuan yangtidak di aplikasikan pupuk cair hayati (P0) justru memiliki jumlah akar sekunder yang lebih tinggi daripada yang diberi pupuk cairhayati (P1). Jumlah akar sekunder tertinggi pada perlakuan tanpa pupuk cair hayati dengan nilai 2,05 .

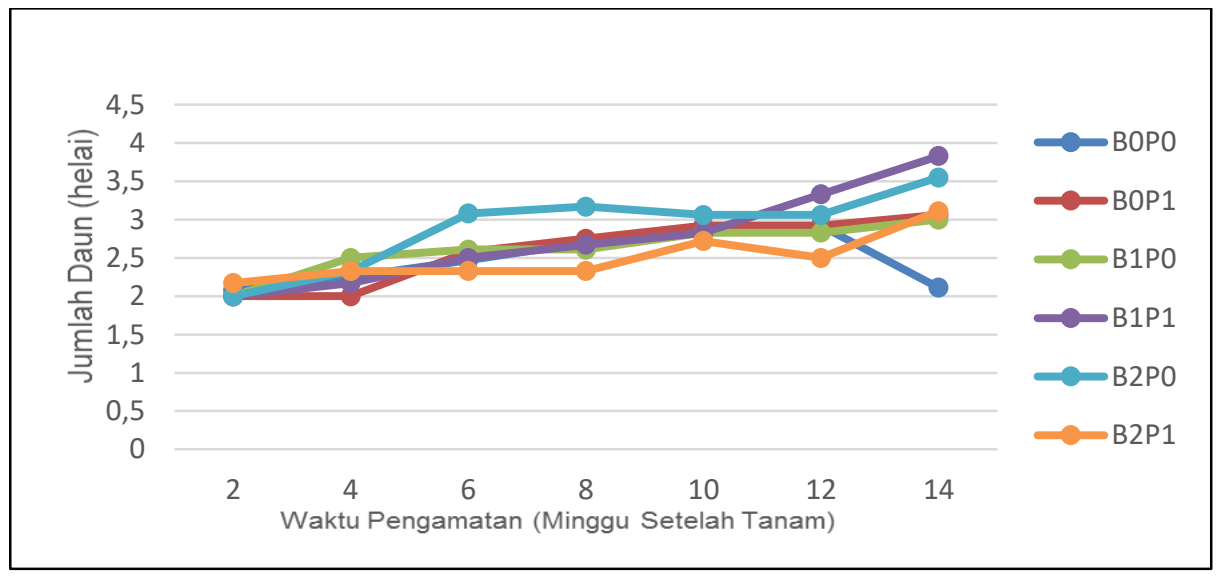

Keterangan:

B0P0 = Tanpa zpt alami dan tanpa pupuk hayati, B0P1 = Tanpa zpt alami dan pupuk cair hayati 120 $\mathrm{ml}, \mathrm{B} 1 \mathrm{P} 0=$ Ekstrak bawang merah $400 \mathrm{~g} / \mathrm{L}$ dan tanpa pupuk hayati, B1P1 = Ekstrak bawang merah $400 \mathrm{~g} / \mathrm{L}$ dan pupuk cair hayati $120 \mathrm{ml}, \mathrm{B} 2 \mathrm{P} 0$ = Ekstrak bawang merah $200 \mathrm{~g} / \mathrm{L}+$ kecambah $200 \mathrm{~g} / \mathrm{L}$ dan tanpa pupuk cair hayati, B2P1 = Ekstrak bawang merah $200 \mathrm{~g} / \mathrm{L}+$ kecambah $200 \mathrm{~g} / \mathrm{L}$ dan pupuk cair hayati $120 \mathrm{ml}$.

Gambar 4. Grafik jumlah daun seedling manggis 
Tabel 2. Hasil uji lanjut BNT pada pengamatan luas daun dan jumlah akar sekunder.

\begin{tabular}{lccc}
\hline Perlakuan & $\begin{array}{c}\text { Luas } \\
\text { daun }\end{array}$ & Perlakuan & $\begin{array}{c}\text { Jumlah akar } \\
\text { sekunder }\end{array}$ \\
\hline B0 & $11,15 \mathrm{~b}$ & $\mathrm{P} 1$ & $1,57 \mathrm{~b}$ \\
$\mathrm{~B} 1$ & $13,2 \mathrm{ab}$ & $\mathrm{P} 0$ & $2,05 \mathrm{a}$ \\
$\mathrm{B} 2$ & $14,65 \mathrm{a}$ & & \\
\hline BNT & 2,78 & & 0,60 \\
\hline
\end{tabular}

Keterangan : B0 = Tanpa zpt alami $0 \mathrm{~g} / \mathrm{L}, \mathrm{B} 1=$ Ekstrak bawang merah $400 \mathrm{~g} / \mathrm{L}, \mathrm{B} 2=$ Ekstrakbawang merah $200 \mathrm{~g} / \mathrm{L}+$ kecambah $200 \mathrm{~g} / \mathrm{L}, \mathrm{P} 0=$ Pupuk cair hayati $0 \mathrm{ml}, \mathrm{P} 1=$ Pupuk cair hayati $120 \mathrm{ml}$.

Tabel 3. Hasil pengamatan pengaruh ekstrak bawang merah dan kecambah dengan pupuk cair hayati pada semua variabel pengamatan seedling manggis.

\begin{tabular}{cccccc}
\hline & \multicolumn{5}{c}{ Variabel Pengamatan } \\
\cline { 2 - 6 } Perlakuan & $\begin{array}{c}\text { Tinggi tanaman } \\
(\mathrm{cm})\end{array}$ & $\begin{array}{c}\text { Jumlah } \\
\text { daun } \\
\text { (helai) }\end{array}$ & $\begin{array}{c}\text { Diameter } \\
\text { batang }(\mathrm{mm})\end{array}$ & $\begin{array}{c}\text { Panjang akar } \\
\text { primer }(\mathrm{cm})\end{array}$ & Bobot segar $(\mathrm{g})$ \\
\hline $\mathrm{B}_{0} \mathrm{P}_{0}$ & 5,42 & 3,00 & 2,43 & 2,23 & 2,41 \\
$\mathrm{~B}_{0} \mathrm{P}_{1}$ & 5,72 & 3,06 & 2,13 & 1,82 & 3,34 \\
$\mathrm{~B}_{1} \mathrm{P}_{0}$ & 5,98 & 3,00 & 2,37 & 2,30 & 3,14 \\
$\mathrm{~B}_{1} \mathrm{P}_{1}$ & 5,49 & 3,83 & 2,57 & 1,82 & 2,89 \\
$\mathrm{~B}_{2} \mathrm{P}_{0}$ & 6,04 & 3,55 & 2,93 & 2,14 & 3,04 \\
$\mathrm{~B}_{2} \mathrm{P}_{1}$ & 5,98 & 3,11 & 2,40 & 1,74 & 2,77 \\
\hline Rata-rata & 5,77 & 3,26 & 2,47 & 2,01 & 2,93 \\
\hline
\end{tabular}

Keterangan : $\mathrm{B} 0 \mathrm{P} 0=$ Tanpa zpt alami dan tanpa pupuk hayati, $\mathrm{B} 0 \mathrm{P} 1=$ Tanpa zpt alami dan pupuk cair hayati $120 \mathrm{ml}, \mathrm{B} 1 \mathrm{P} 0$ = Ekstrak bawang merah $400 \mathrm{~g} / \mathrm{L}$ dan tanpa pupuk hayati, $\mathrm{B} 1 \mathrm{P} 1=$ Ekstrak bawang merah $400 \mathrm{~g} / \mathrm{L}$ dan pupuk cair hayati $120 \mathrm{ml}, \mathrm{B} 2 \mathrm{P} 0=$ Ekstrak bawang merah $200 \mathrm{~g} / \mathrm{L}+$ kecambah $200 \mathrm{~g} / \mathrm{L}$ dan tanpa pupuk cair hayati, B2P1 = Ekstrak bawang merah $200 \mathrm{~g} / \mathrm{L}+$ kecambah $200 \mathrm{~g} / \mathrm{L}$ dan pupuk cair hayati $120 \mathrm{ml}$.

\section{Panjang Akar Primer}

Hasil analisis ragam menunjukkan bahwa pemberian zat pengatur tumbuh alami dan pupuk cair hayati tidak berpengaruh nyata terhadap variabel pengamatan panjang akar primer. Rata-rata panjang akar primer pada 14 MST yaitu sebesar 2,01 $\mathrm{cm}$. Kisaran panjang akar primer tertinggi yaitu $2,30 \mathrm{~cm}$ pada perlakuan B1P0 (ekstrak bawang merah400 $\mathrm{g} / \mathrm{l}+$ tanpa pemberian pupuk cair $0 \mathrm{ml} / \mathrm{l}$ ), dan kisaran terendah sebesar 1,74 cmpada perlakuan B2P1 (campuran ekstrak bawang merah $200 \mathrm{~g} / \mathrm{L}$ dan kecambah $200 \mathrm{~g} / \mathrm{L}$ dengan pemberian pupuk cair hayati 15 $\mathrm{ml} / \mathrm{L})$.

\section{Bobot Segar}

Hasil analisis ragam menunjukkan bahwa pemberian zat pengatur tumbuh alami dan pupuk cair hayati tidak berpengaruh nyata terhadap variabel pengamatan bobot segar seedling manggis. Rata-rata bobot segar seedling manggis pada pengamatan 14 MST sebesar 2,93 g dengan kisaran tertinggi pada perlakuan B0P1 (tanpa zat pengatur tumbuh $0 \mathrm{~g} / \mathrm{l}$ dengan pupuk cair $15 \mathrm{ml} / \mathrm{l}$ ) sebesar $3,34 \mathrm{~g}$ 
dan terendah pada perlakuan B0P0 (Kontrol) sebesar 2,41 g.

\section{Pembahasan}

Berdasarkan hasil penelitian yang dilakukan menunjukkan bahwa pemberian zat pengatur tumbuh alami ekstrak bawang merah tunggal dan campuran ekstrak bawang merah dengan kecambah hanya berpengaruh nyata pada luas daun, sedangkan pemberian pupuk cair hayati dapat meningkatkan jumlah akar sekunder pada seedling manggis. Perlakuan zat pengatur tumbuh alami dan pupuk hayati kurang berpengaruh karena diduga ada beberapa sebab diantaranya: waktu pengaplikasian yang kurang tepat, umur pindah tanam, waktu pengamatan yang relatif singkat, dan adanya serangan hama uret.

Pemberian ZPT alami hanya memberikan pengaruh pada luas daun dan pemberian pupuk cair hayati berpengaruh pada jumlah akar sekunder, sedangkan kedua perlakuan tidak menunjukkan adanya interaksi, hal ini dikarenakan pengaplikasian yang dilakukan saat seedlings manggis berumur 4 minggu setelah tanam. Pada umur ini akar seedling manggis masih belum berkembang secara sempurna karena baru muncul akar tunggang. Berdasarkan penelitian Rugayah (2021) pengaplikasian zat pengatur tumbuh ekstrak bawang merah dan ekstrak tomat pada seedling manggis berumur delapan minggu setelah tanam berpengaruh meningkatkan diameter batang, luas daun, tingkat kehijauan daun, dan bobot segar tanaman. Pengaplikasian ZPT alami pada umur 8 MST terlihat lebih banyak memberikan pengaruh nyata terhadap variabel pengamatan dibandingkan dengan pengaplikasian pada 4 MST.

Umur pindah tanam juga mempengaruhi pertumbuhan seedling manggis. Sebelum pengaplikasian ZPT alami dan pupuk cair hayati seedling manggis dipindah tanam dari media semai ke polybag untuk mengurangi kerusakan pada akar. Menurut Delliana et al. (2017), seedling manggis yang ditanam secara langsung berpotensi untuk tumbuh lebih baik dibandingkan dengan cara pindah tanam. Apabila menggunakan teknik pindah tanam maka tanaman akan mengalami kerusakan pada akar yang menyebabkan tanaman kesulitan untuk tumbuh optimal. Pindah tanam pada umur muda sebelum akar lateral berkembang diharapkan agar tanaman tidak mengalami stagnasi sehingga penyerapan ZPT alami dapat berjalan optimum. Selain itu pindah tanam yang dilakukan saat umur seedling masih muda dapat mengurangi kerusakan pada akar. Bibit tidak memberikan respon terhadap pemberian ZPT alami karena keterbatasan akar. Berdasarkan hasil pengamatan pindahtanam pada umur 4 MST perkembangan akar sekunder belum terbentuk, sehingga menyebabkan penyerapan ZPT alami yang diberikan melalui media tanam kurang efektif. Hasil ini dapat dilihat dari pengamatan jumlah akar sekunder yang belum menunjukkan adanya perkembangan yang signifikan.

Waktu pengamatan yang singkat belum menunjukkan adanya pengaruh yang signifikan dari perlakuan yang diberikan terhadap pertumbuhan seedling manggis. Menurut Rugayah (2021) pembibitan tanaman manggis yang berasal dari biji memerlukan waktu 2 tahunan untuk siap tanam, apabila sudah keluar cabang lateral dengan tinggi $60 \mathrm{~cm}$, sedangkan pada penelitian ini pengamatan yang dilakukan hanya selama 14 MST sehingga menyebabkan pengaruh dari perlakuan yang diberikan belum terlihat sepenuhnya.

Hama uret (Lepidiota stigma F.) yang ditemukan pada media tanam seedling manggis diduga berasal dari pupuk kompos yang belum steril sehingga membawa telurtelur uret, kemudian berkembang menjadi larva saat media tanam sudah tercampur dan merusak akar seedling manggis. Hama uret menyerang pada bagian akar tanaman, apabila tidak segera dikendalikan dapat menyebabkan akar tanaman terpotong, 
akibatnya tanaman akan tampak layu, menguning mirip gejala kekeringan, kemudian mati.Tanaman yang mati terserang uret, karena akarnya terpotong dimakan oleh uret tersebut (Ulya et al., 2016). Pada penelitian ini hama uret dikendalikan dengan menggunakan insektisida berbahan aktif karbofuran $3 \%$. Aplikasi dilakukan dengan cara ditabur di atas permukaan media tanam, akan tetapi pada pengamatan terakhir masih terdapat hama uret saat media dibongkar.

Jumlah akar sekunder pada tanpa pemberian pupuk hayati lebih tinggi daripada yang menggunakan pupukhayati. Hal ini terlihat dari adanya indikasi serangan awal pada perlakuan B1P1 (ekstrak bawang merah $400 \mathrm{~g} / \mathrm{l}+$ dengan pupuk hayati $15 \mathrm{ml} / \mathrm{l})$. Uret memakan akar pada tanaman yang diaplikasikan dengan pupuk cair hayati dibandingkan tanpa pemberian pupuk cair hayati. Hama uret lebih condong berada pada lingkungan hidup dengan kandungan bahan organik tinggi. Lingkungan yang mempunyai kandungan bahan organik tinggi mudah di tembus oleh berbagai stadia OPT tanah (Setiawati, 2014). Larva uret sangat cocok berkembang pada kondisi tersebut sebagai tempat hidup.

Pada variabel pengamatan jumlah daun, pertumbuhannya menunjukkan perkembangan yang sangat lambat. Jumlah daun pada pengamatan 14 MST rata-rata adalah tiga helai daun. Menurut Fitter dan Hay (2002), lamanya pertumbuhan daun tergantung pada suhu dimana semakin tinggi suhu maka durasinya semakin pendek, sedangkan laju ekspansi (perluasan) daun tergantung pada tekanan turgor daun dan karakteristik dinding sel. Suhu udara yang tinggi $\left(35-40^{\circ} \mathrm{C}\right)$ cenderung meningkatkan laju transpirasi yang dapat berakibat pada menurunnya kandungan air tanah yangpada akhirnya dapat menurunkan kandungan air dan tekanan turgor di dalam daun, sehingga laju ekspansi (perluasan) daun menjadi terhambat.
Pada variabel pengamatan diameter batang belum menunjukkan adanya pertumbuhan yang signifikan pada seedling manggis. Pada variabel bobot segar tanaman, seedling manggis dengan perlakuan tanpa ZPT alami dan penambahan pupuk cair hayati menghasilkan bobot segar tanaman tertinggi dibandingkan dengan perlakuan lain. Peningkatan bobot segar seedling manggis kemungkinan dipengaruhi oleh variabel yang tidak diamati yaitu ketebalan daun dan ketebalan akar.

Media tanam yang digunakan berupa kompos dan pupuk kandang yang dapat memperbaiki kesuburan tanah. Menurut Amir et al. (2017) pupuk kandang adalah pupuk yang berasal dari kotoran hewan baik padat maupun cair dan sisa-sisa makanan, contohnya kotoran sapi, kuda, kerbau, kambing dan lain-lain. Hasil buangan binatang ini kemudian mengalami pembusukkan dan menjadi pupuk yang baik dan dapat digunakan untuk menambah hara sekaligus memperbaiki sifat fisik dan biologi tanah.

Pupuk hayati adalah alternatif untuk memanfaatkan mikroorganisme tertentu dalam jumlah yang banyak untuk menyediakan hara serta membantu pertumbuhan tanaman, dengan cara menambat nitrogen yang cukup besar dari udara dan membantu tersedianya fosfor dalam tanah (Sinulingga et al., 2015). Berdasarkan hasil analisis media tanam yang digunakan menunjukkan bahwa tanpa pemberian pupuk cair hayati maupun dengan aplikasi pupuk cair hayati memiliki kandungan unsur hara yang tinggi. Hal ini sesuai dengan kriteria sifat kimia tanah yang dinyatakan oleh Eviati dan Sulaeman (2009). Analisis media tanam yang dilakukan meliputi N-total (\%), C-Organik (\%), pH, P-tersedia (ppm), dan $\mathrm{K}_{2} \mathrm{O}(\%)$.

Kandungan kedua media tanam berdasarkan kriteria sifat kimia tanah menurut Eviati dan Sulaeman (2009) memiliki tingkat kesuburan yang tinggi. Analisis kandungan media tanpa pupuk cair 
hayati di laboratorium ilmu tanah (2020) mengandung $\mathrm{N}$-total $0,81 \%$, C-organik sebesar 7,42 \%, P-tersedia 688,20 ppm, dan $\mathrm{K}_{2} \mathrm{O}$ sebesar 3,04\%, sedangkan pada perlakuan dengan pemberian pupuk cair hayati kadar $\mathrm{N}$-total $0,75 \%$, C-organik sebesar 8,39\%, P-tersedia 668,54 ppm, dan $\mathrm{K}_{2} \mathrm{O}$ sebesar $3,22 \%$. Kriteria sifat kimia tanah pada kategori sangat tinggi menurut Eviati dan Sulaeman (2009) yaitu $N \geq 0,75$ $\%, \mathrm{C} \geq 5 \%, \mathrm{P} 2 \mathrm{O} 5 \geq 15 \mathrm{ppm}$, dan $\mathrm{K} \geq 1$ me/100 mg.

Pupuk cair hayati yang digunakan memiliki memiiki $\mathrm{pH}$ sebesar 5,76 sangat sesuai untuk pertumbuhan tanaman manggis. Tanaman manggis mampu tumbuh dari dataran rendah sampai ketinggian $\pm 600 \mathrm{mdpl}$, suhu udara berkisar antara $38^{\circ} \mathrm{C}-40^{\circ} \mathrm{C}$, dan tingkat keasaman $(\mathrm{pH})$ tanah berkisar 5-7 (Nidyasari et al., 2018). Pada lahan dengan $\mathrm{pH}$ asam seperti di lahan gambut, manggis tetap mampu tumbuh dengan baik.

Hasil dari penelitian ini menunjukkan bahwa pertumbuhan seedling manggis dipengaruhi oleh beberapa faktor, di antaranya pengaplikasian ZPT alami dan pupuk cair hayati yang kurang optimal karena dilakukan pada umur 4 MST, akar yang belum berkembang secara sempurna kurang optimal dalam menyerap ZPT dan pupuk cair hayati yang diberikan. Seedling manggis yang dipindah tanam harus beradaptasi dengan lingkungan tumbuhyang baru. Adanya serangan hama uret yang memakan akar sangat mempengaruhi pertumbuhan seedling manggis. Waktu pengamatan yang singkat yaitu 3,5 bulan juga belum menunjukkan adanya pengaruh yang signifikan dari perlakuan yang diberikan terhadap pertumbuhan seedling manggis. Walaupun demikian masih ada harapan untuk menggunakan campuranZPT alami bawang merah dan kecambah, serta penggunaan pupuk kompos sebagai campuran media tanam yang harus disterilkan terlebih dulu.

\section{KESIMPULAN}

Dari hasil penelitian ini dapat disimpulkan bahwa:

(1) Pemberian ekstrak bawang merah tunggal dan campuran bawang merah dengan kecambah menghasilkan pertumbuhan yangtinggi pada luas satu daun terlebar seedling manggis. Perlakuan campuran bawang merah dengan kecambah memberikan pengaruh tertinggi. Selisih pertumbuhan luas satu daun terlebar pada perlakuan campuran bawang merah dengan kecambah dengan perlakuan kontrol yaitu $3,5 \mathrm{~cm}^{2}$.

(2) Pemberian pupuk cair hayati berpengaruh pada variabel jumlah akar, namun justru pada perlakuan tanpa pupuk cair hayati memiliki jumlah akar yang lebih banyak daripada yang diaplikasikan pupuk cair hayati.

(3) Interaksi antara pemberian ekstrak bawang merah dan kecambah dengan pupuk cair hayati tidak menunjukkan pengaruh yang nyata terhadap pertumbuhan seedling manggis.

\section{DAFTAR PUSTAKA}

Aizat, W.M., Ahmad-Hashim, F.H. and Jaafar, S.N.S., 2019. Valorization of mangosteen, "The Queen of Fruits," and new advances in postharvest and in food and engineering applications: A review. Journal of Advanced Research, 20: 61-70.

Amir, N., Hawalid, H., dan Nurhuda, I.A. 2017. Pengaruh pupuk kandang terhadap pertumbuhan beberapa varietas bibit tanaman tebu (Saccharum officinarum L.) di polybag. Jurnal UM Palembang. 12 (2): 68-72.

Delliana, D., Al-Hamidy, N., Rugayah, dan Karyanto, A. 2017. Pengaruh konsentrasi IBA (Indole 3 Butyric Acid) dan teknik penyemaian terhadap pertumbuhan bibit manggis (Garciniamangostana L.) asal biji. Jurnal AgrotekTropika. 5 (3): 132137. 
Direktorat Jenderal Hortikultura. 2019. Laporan Kinerja Direktorat Jenderal Hortikultura Tahun 2019. http://hortikultura.pertanian. go.id/wp-content/uploads/2020/06/LakinDitjen-Hortikultura-TA-2019.pdf.

Einhelig, F.A. 2004. Allelopathy: Organisms, Processes, and Applications. Washington DC: American Chemical Society. p 217 238.

Eviati dan Sulaeman. 2009. Analisis kimia tanah, tanaman, air, dan pupuk. BalaiPenelitian Tanah. Bogor. 246 hlm.

Fitter, A.H. dan Hay, R. 2001. Enviromental Physiology of Plants. 3rd edition. Academis Press San Diego. USA. 367 hlm.

Nabila, T. N., Rugayah, Karyanto, A., dan Widagdo, S. 2020. Pengaruh jenis dan konsentrasi zat pengatur tumbuh alami pada pertumbuhan seedling manggis (Garcinia mangostana L.). Jurnal Agrotek Tropika. 8 (3): 493-500.

Nidyasari, RR.S, Akmal, H, dan Ariyanti, N.S. 2018. Karakterisasi morfologi dan anatomi tanaman manggis dan kerabatnya (Garcinia spp.) di Taman Buah Mekarsari. Jurnal SumberdayaHatyati. 4(1): 12-20.

Pamungkas S.S.T dan Nopiyanto, R. 2020. Pengaruh zat pengatur tumbuh alami dari ekstrak tauge terhadap pertumbuhan pembibitan budchip tebu (Saccharum officinarum L.) varietas Bululawang (BL). Mediagro, 16 (1): 68-80.

Rugayah, Suherni, D., Ginting, Y.C., dan Karyanto, A. 2021. Pengaruh konsentrasi ekstrak bawang merah dan tomat pada pertumbuhan seedling manggis (Garcinia mangostana L.). J. Hort. Indonesia. 12 (1): $42-50$.

Setiawati, W., Hudayya, A., dan Jayanti, H. 2014. Distribusi dan kelimpahan populasi orong-oromg (Gryllotalpa hirsuta Burmeister.), uret (Phyllophaga javana
Brenske.), dan ulat tanah (Agrotis ipsilon Hufnagel.) di sentra produksi kentang di Jawa Barat dan Jawa Tengah. J. Hort. 24 (1): 65-75.

Sinulingga E. S. R., Ginting, J., dan Sabrina, T. 2015. Pengaruh pemberian pupuk hayati cair dan pupuk NPK terhadap pertumbuhan bibit kelapa sawit di pre nursery. Jurnal Online Agroteknologi. 3 (3): 1219-1225.

Sofwan, N., Faelasofa, O., Triatmoko, A. H., dan Iftitah, S. N. 2018. Optimalisasi ZPT (zat pengatur tumbuh) alami ekstrak bawang merah (Allium cepa fa. Ascalonicum) sebagai pemacu pertumbuhan akar stek tanaman buah tin (Ficus carica). Jurnal Ilmu Pertanian Tropika dan Subtropika. 3 (2): 46-48.

Syah, M.J.A., Muas, I. dan Herizal, Y. 2007. Pemanfaatan Cendawan Mikroza Arbuskula Untuk Memacu Pertumbuhan Bibit Manggis. Tabloid Sinar Tani. Balai Penelitian Tanaman Buah Tropika. Puslitbanghorti. Bogor. 3 hlm.

Tarigan, P. L., Nurbaiti, dan Yoseva, S. 2017. Pemberian ekstrak bawang merah sebagai zat pengatur tumbuh alami pada pertumbuhan setek lada (Piper nigrum L.). JOM FAPERTA, 4 (1): 2-10.

Ulya, L.N, Himawan, T, dan Mudjiono, G. 2016. Uji patogenitas jamur entomopatogen Metarhizium anisopliae (Moniliales: Moniliaceae) terhadap hama uret Lepidiota stigma f. (coleoptera: Scarabaeidae). Jurnal HPT. 4 (1): 24-31.

Yanengga, Y., dan Tuhuteru, S. 2020. Aplikasi ekstrak bawang merah terhadap pertumbuhan okulasi tanaman jeruk manis (Citrus Sp.). Jurnal Agritech. 22 (2): 7887. 